\title{
Mycotic aneurysm at site of formerly ligated ductus arteriosus caused by infective endarteritis
}

\author{
J HESS, M TH E BINK-BOELKENS, J DANKERT \\ From the Department of Paediatrics, Division of Paediatric Cardiology, and Laboratory for Medical Microbiology, \\ Department of Hospital İnfections, University Hospital, Groningen, The Netherlands
}

SUMMARY A mycotic aneurysm caused by infective endarteritis occurred at the site of a formerly ligated ductus arteriosus. Because of external pressure by the aneurysm upon the aorta, the clinical syndrome of coarctation of the aorta was mimicked. After antibiotic treatment successful surgery was performed.

The risk of developing infective endocarditis in relation to a pre-existing cardiac lesion varies according to the lesion. In persistent ductus arteriosus it is approximately one in every 300 patient-years. Assuming a 70 year life a patient with persistent ductus arteriosus has a $20 \%$ risk of developing infective endocarditis. After surgical closure it is presumed that this risk declines to that of a healthy individual ${ }^{1}$ and that antibiotic prophylaxis can be omitted after the early postoperative period. ${ }^{23} \mathrm{We}$ describe a patient who developed a mycotic aneurysm of the descending aorta caused by infective endarteritis at the site of a persistent ductus arteriosus which had been ligated 11 years earlier.

\section{Case report}

A 12-year-old girl was admitted to hospital because of pyrexia, malaise, weight loss, and diffuse arthralgia of four weeks' duration. She had been treated with oral penicillin elsewhere for one week. A small membranous ventricular septal defect was known to be present and she had had a large persistent ductus arteriosus ligated at the age of 1 year. Cardiac recatheterisation at the age of 9 years had shown a pulmonary systemic flow ratio of $1.4: 1$, with a normal pulmonary artery pressure. Left ventriculár angiography had shown the small defect in the membranous interventricular septum. The aorta was normal.

On admission, physical examination showed a pale, ill-looking girl, weighing $34.5 \mathrm{~kg}$, with a body temperature of $39^{\circ} \mathrm{C}$. There was pretibial oedema, slightly swollen painful ankle joints, and a nonspecific erythema on the legs. The arm blood pressure was $145 / 95 \mathrm{mmHg}$ bilaterally and the systolic blood pressure in the legs was $100 \mathrm{mmHg}$. The radial pulses were easily palpable, in contrast to the femoral pulses. The spleen was enlarged. In the fourth left intercostal space a grade $3 / 6$ pansystolic murmur was heard and in the second left intercostal space there was a grade $2 / 6$ ejection murmur, radiating to the back. There were no other abnormal findings, exept for the presence of some diseased teeth. Laboratory data on admission included the following: erythrocyte sedimentation rate $65 \mathrm{~mm} / \mathrm{hr}$, haemoglobin $10.6 \mathrm{~g} / 100$ $\mathrm{ml}$, white blood cell count $11000 / \mathrm{mm}^{3}$, thrombocytes $357000 \mathrm{~mm}^{3}$, blood urea nitrogen $12.3 \mathrm{mmol} / \mathrm{l}$ (74 $\mathrm{mg} / 100 \mathrm{ml})$, creatinine $300.6 \mathrm{mmol} / 1(3.4 \mathrm{mg} / 100 \mathrm{ml})$, gamma-globulin $20.1 \mathrm{mg} / \mathrm{ml}$, total protein $8.0 \mathrm{~g} / 100$ $\mathrm{ml}$. Examination of the urine disclosed proteinuria, leucocytes, and red cells, with some red cell casts.

The electrocardiogram was normal. On chest $x$-ray examination the heart was slightly enlarged to the left and the descending aorta showed a pronounced dilatation over a distance of about $5 \mathrm{~cm}$. The echocardiogram was normal. An aneurysm of the descending aorta was suspected, possibly caused by infective endarteritis at the site of the previously ligated persistent ductus arteriosus. The signs of coarctation of the aorta, which were definitely new, were presumed to be caused by the aneurysm. It was felt she also had glomerulonephritis. After blood samples had been taken for anaerobic and aerobic cultures, antibiotic treatment was started immediately: $30000000 \mathrm{U}$ penicillin $\mathrm{G}$ intravenously daily for six weeks, and 700 mg streptomycin intramuscularly daily for two weeks. All cultures proved to be sterile. In the first week of treatment the erythrocyte sedimentation rate gradually returned to normal, the arthralgias disappeared, 
body temperature became normal, and renal function improved.

Cardiac catheterisation was performed one week after the completion of treatment. The left ventricular angiogram again showed the small membranous ventricular septal defect. The aortogram showed an irregular aneurysm in front of and pressing on the descending aorta (Fig.).

At operation one week later the aneurysm was found to have its origin at the site of the formerly ligated persistent ductus arteriosus. There was no communication between the aorta and the pulmonary artery. The aneurysm extended downwards and compressed the aortic wall from the outside, narrowing the inner diameter of the aorta over a distance of $1 \mathrm{~cm}$. In order to resect the aneurysm and the surrounding tissue the aorta had to be clamped proximally and distally, which required axillofemoral bypass. $A$ "dacron" woven graft was inserted. On histological examination of the excised tissue a chronic inflammatory reaction was seen. Aerobic and anaerobic cultures of a tissue specimen remain sterile.

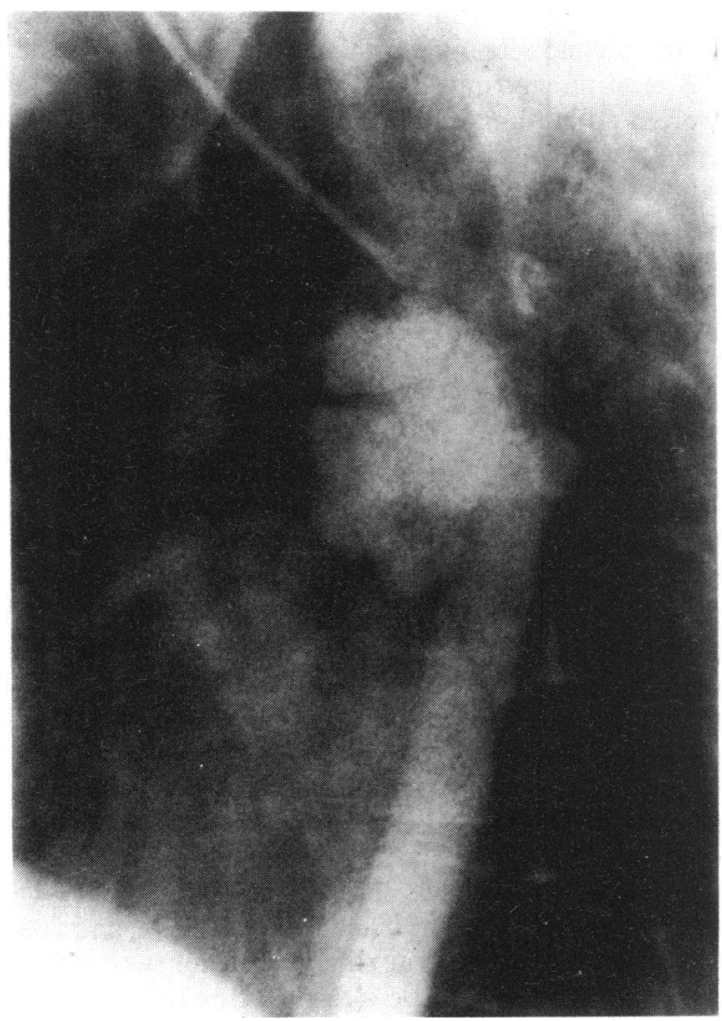

Fig. Aortogram (left oblique view) showing an irregular anewrysm in fromt of and pressing on the descending aorta.
Two years after operation the girl is well and her $\stackrel{C}{.}$ blood pressure is $110 / 70 \mathrm{mmHg}$.

\section{Discussion}

Surgical closure of the persistent ductus arteriosus has $\frac{0}{\bar{D}}$ a very low mortality and is therefore advised even in a patient whose ductus carries a haemodynamically ${ }^{\circ}$ insignificant shunt to eliminate the relatively high risk $\overrightarrow{0}$ of developing infective endocarditis. ${ }^{4}$ Recanalisation $\vec{\overrightarrow{ }}$ or incomplete closure of a persistent ductus that has $\stackrel{\omega}{\sim}$ been only ligated occurs infrequentlys and in such patients the risk of infective endocarditis remains high, ${ }^{6}$ the site of infection being the usual one local-. ised at the pulmonary end of the ductus. ${ }^{7}$ In our patient the ligated ductus has been proved to be $\omega$ closed but a mycotic aneurysm had developed in the descending aorta at its former site. This suggests that this area remained an endocarditis prone lesion. More ${ }_{\rho}^{c}$ than $90 \%$ of mycotic aneurysms are the result of infec- $?$ tive endocarditis, a complication produced by infected microemboli passing into the vasa vasorum. A minority of mycotic aneurysms originate in arteries $\stackrel{\infty}{\infty}$ at the site of previously injured endothelium by direct ${ }^{N}$ seeding of micro-organisms. ${ }^{8}$ It might be argued that ${ }^{\circ}$ in our patient the aneurysm was secondary to endocarditis on the ventricular septal defect but in this condition the vegetations are generally localised on the right ventricular side of the septum or on the $\stackrel{\square}{2}$ endocardium in the right ventricle opposite the $\overrightarrow{\vec{O}}$ defect, ${ }^{7}$ and in the absence of right-to-left shunting, 3 as was the case here, infected emboli from these areas? are not very likely to enter the systemic circulation. Furthermore there were no signs of intracardiac vegetations on echocardiography. Thus, it is probable that the endocarditis in our patient was primarily the? result of an endarteritis causing direct seeding of 3 . micro-organisms on previously injured endothelium at the site of the ligated ductus. The source of these micro-organisms could have been dental but unfortu-o nately blood cultures remained sterile, possibly? because penicillin had been given before admission. 9 음 The treatment we gave of penicillin in high dosage, in combination with streptomycin, was that indicated in $\sigma$ patients with culture negative endocarditis. ${ }^{10}$

Resection of the aneurysm in our patient was per-N formed after completion of antibiotic treatment. This $\sigma$ is recommended, 11 but is not always successful, since persistence of the aortitis can occur despite adequate blood levels of antibiotics. Because of this and the risk of aneurysmal rupture immediate operation is possible ${ }^{12}$ and will be preferred by us in future cases. This case illustrates that infective endocarditis can still $\overrightarrow{\mathbb{D}}$ occur after surgical closure of a persistent ductus $\vec{D}$ arteriosus, even after 11 years. Such patients should $\stackrel{\bigcirc}{\square}$ be followed long term and it may not be as safe to omit 
antibiotic prophylaxis against bacterial endocarditis in them as is generally accepted.

\section{References}

1 Espino-Vela J, Cardenas N, Cruz R. Patent ductus arteriosus. Circulation 1968; 38, suppl 5: 45-60.

2 Rosenthal A, Nadas AS. Infective endocarditis in infancy and childhood. In: Rahimtoola SH, ed. Infective endocarditis. New York, San Francisco, London: Grune \& Stratton, 1978: 149-78.

3 Kaplan, EL, Anthony BF, Bisno A, et al. Prevention of bacterial endocarditis. Circulation 1977; 56: 139A-43A.

4 Morriss JH, McNamara DG. Residua, sequelae, and complications of surgery for congenital heart disease. In: Rosenthal A, Sonnenblick. EH, Lesch M, eds. Postoperative congenital heart disease. New York, San Francisco, London: Grune \& Stratton, 1975: 3-27.

5 Panagopoulos PG, Tatooles CJ, Aberdeen E, Waterston DJ, Bonham Carter RE. Patent ductus arteriosus in infants and children. A review of 936 operations (19461969). Thorax 1971; 26: 137-44.

6 Gross RE. Complete division for the patent ductus arteriosus. F Thorac Surg 1947; 16: 314-27.
7 Nadas AS. Bacterial endocarditis. In: Nadas AS, Fyler DC, eds. Pediatric cardiology. 3rd ed. Philadelphia, London, Toronto: W B Saunders, 1972; 182-90.

8 Durack DT, Beeson PB. Pathogenesis of infective endocarditis. In: Rahimtoola SH, ed. Infective endocarditis. New York, San Francisco, London: Grune \& Stratton, 1978: 1-53.

9 Pesanti EL, Smith IM. Infective endocarditis with negative blood cultures. Am f Med 1979; 66: 43-50.

10 Weinstein L, Schlesinger J. Treatment of infective endocarditis 1973. Prog Cardiovasc Dis 1973; 16: 275302.

11 Schneider JA, Rheuban KS, Crosby IK. Rupture of postcoarctation mycotic aneurysms of the aorta. Ann Thorac Surg 1979; 27: 185-90.

12 Okies JE, Starr A. Cardiac surgery in infective endocarditis. In: Rahimtoola SH, ed. Infective endocarditis. New York, San Francisco, London: Grune \& Stratton, 1978: 361-77.

Requests for reprints to Dr John Hess, Division of Paediatric Cardiology, University Hospital, 59 Oostersingel, 9713 EZ Groningen, The Netherlands. 